\title{
The Hall current system revealed as a statistical significant pattern during fast flows
}

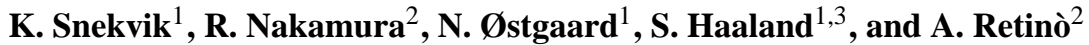 \\ ${ }^{1}$ Department of Physics and Technology, University of Bergen, Bergen, Norway \\ ${ }^{2}$ Space Research Institute, Austrian Academy of Sciences, Graz, Austria \\ ${ }^{3}$ Max-Planck-Institut für Extraterrestrische Physik, Garching, Germany
}

Received: 7 May 2008 - Revised: 16 September 2008 - Accepted: 19 September 2008 - Published: 5 November 2008

\begin{abstract}
We have examined the dawn-dusk component of the magnetic field, $B_{Y}$, in the night side current sheet during fast flows in the neutral sheet. $237 \mathrm{~h}$ of Cluster data from the plasma sheet between 2 August 2002 and 2 October 2002 have been analysed. The spatial pattern of $B_{Y}$ as a function of the distance from the centre of the current sheet has been estimated by using a Harris current sheet model. We have used the average slopes of these patterns to estimate earthward and tailward currents. For earthward fast flows there is a tailward current in the inner central plasma sheet and an earthward current in the outer central plasma sheet on average. For tailward fast flows the currents are oppositely directed. These observations are interpreted as signatures of Hall currents in the reconnection region or as field aligned currents which are connected with these currents. Although fast flows often are associated with a dawn-dusk current wedge, we believe that we have managed to filter out such currents from our statistical patterns.
\end{abstract}

Keywords. Magnetospheric physics (Current systems; Magnetotail; Plasma convection)

\section{Introduction}

Fast flows in the magnetotail typically refer to flows with a magnitude larger than a few hundred $\mathrm{km} / \mathrm{s}$ (Baumjohann et al., 1989, 1990). In a statistical study, Raj et al. (2002) showed that fast flows can be separated into two groups based on their distribution functions, namely field aligned beams (FABs) and bulk flows. The last group is more commonly referred to as bursty bulk flows (BBFs) (Angelopoulos et al., 1992, 1994). BBFs are characterized by flow bursts $(V>400 \mathrm{~km} / \mathrm{s}$ ) lasting less than $10 \mathrm{~s}$ (Baumjohann et al., $1990)$ embedded in slower moving plasma $(V>100 \mathrm{~km} / \mathrm{s})$

Correspondence to: K. Snekvik

(kristian.snekvik@uib.no) with an average duration of about $18 \mathrm{~min}$ (Cao et al., 2006). FABs and BBFs are mainly localized in the outer and inner plasma sheet, respectively, although a considerable region of overlap exists (Raj et al., 2002). Note that fast flows in the central plasma sheet have been given various names in the literature. In this paper, the name BBF is used rather loosely as the common description of convective transport of plasma in the central plasma sheet.

BBFs are believed to be a major contributor to flux transport in the near Earth tail $\left(-10 R_{E}<X_{\mathrm{GSM}}<-20 R_{E}\right.$ ) (Angelopoulos et al., 1994; Schödel et al., 2001) as part of the Dungey cycle (Dungey, 1961). In this picture magnetic field lines are reconnected in the highly stretched tail and the plasma is accelerated away from the X-line in opposite directions. A flow reversal can therefore be used as an indirect observation of an X-line. Statistical studies of the fast flows (Nagai and Machida, 1998; Nagai et al., 1998, and references therein) indicate that the reconnection region, where such flow reversals take place, is located between 20 and $30 R_{E}$ tailward of the Earth.

Due to the different scale lengths which demagnetize ions and electrons in a collision free plasma, Hall-currents will be set up in the reconnection region as first proposed by Sonnerup (1979). These currents are by definition perpendicular to the magnetic field. Treumann et al. (2006) developed a theoretical framework for how the divergence of the Hall currents leads to generation of field aligned currents. $\mathrm{Ob}$ servations of the field aligned currents were done by Nagai and Machida (1998) and Nagai et al. (2001) as low energy field aligned electrons $(<5 \mathrm{keV})$ carrying a current out of the reconnection region near the plasma sheet/lobe boundary. Accelerated electrons $(>10 \mathrm{keV})$ away from the X-line were also commonly observed. The Hall currents and the field aligned currents which close with them, were called the Hall current system by Nagai et al. (2001), hence we adopt this terminology here. This current system gives a characteristic quadrupolar signature in the dawn-dusk component

Published by Copernicus Publications on behalf of the European Geosciences Union. 


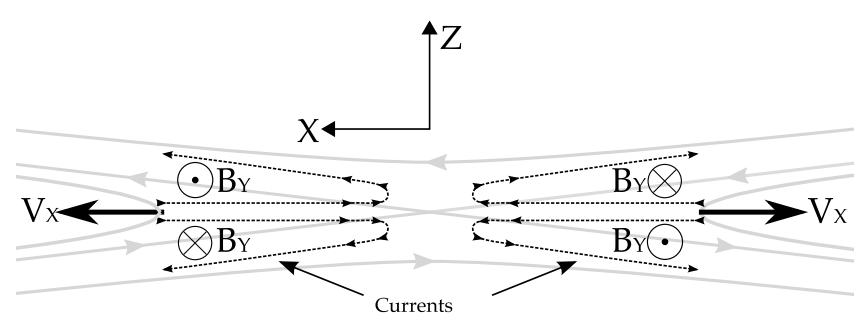

Fig. 1. The quadupolar signature in $B_{Y}$ created from the Hall current system around a X-line. Adopted from Sonnerup (1979).

of the magnetic field, $B_{Y}$, which has been observed in the vicinity of the X-line (e.g. Runov et al., 2003). The charge separation associated with the Hall currents is believed to set up an electric field towards the neutral sheet in the inflow region which gives an observed dawnward component of the ion velocity (Nagai et al., 2001). Figure 1 illustrates the Hall current system around an X-line and the quadrupolar signature of $B_{Y}$.

A 3-D Hall-MHD simulation by Yamade et al. (2000) has shown that the Hall current system may contribute significantly to the global field aligned current pattern. Several observations support this. Fujimoto et al. (2001) found that a tailward electron beam is often seen near the lobe during dipolarization in the near-Earth plasma sheet. For Cluster at about $X_{\mathrm{GSM}}=-10 R_{E}$, Nakamura et al. (2004b) observed field aligned currents, velocity shear and field aligned electrons close to the boundary between the plasma sheet and the lobe. The Hall current system could explain these observations very well. Polar has observed large northsouth electric fields and associated dawn-dusk perturbations of the magnetic field in the outer plasma sheet near the Earth $\left(-7 R_{E}<X_{\mathrm{GSM}}<-4 R_{E}\right)$ (Wygant et al., 2000; Keiling et al., 2001). In some of the events the electric fields appeared to occur at the edge of a field-aligned current sheet as one would expect from the Hall current system. Runov et al. (2008) made detailed observations of successive tailward flow bursts. During the flow enhancements the magnetic field turned dawnward and duskward in the Northern and Southern Hemisphere, respectively. The signs of $B_{Y}$ corresponded to the tailward part of the quadrupolar magnetic structure due to the Hall current system near the X-line.

Although the Hall current system is a well established concept around the reconnection region, it still remains to establish how the currents extend away from the X-line. In order to further investigate the Hall current system away from the reconnection region, we examine $B_{Y}$ perturbations statistically during fast flows in the neutral sheet. We take advantage of the 4 identical spacecraft $(\mathrm{C} 1, \mathrm{C} 2, \mathrm{C} 3$ and $\mathrm{C} 4)$ from the Cluster mission. This enables us to monitor the plasma sheet boundary layer and the inner and outer central plasma sheet, simultaneously with fast flows in the neutral sheet. The reason for restricting fast flows to the neutral sheet only, is to discriminate between field aligned beams and bulk flows. According to the study by Raj et al. (2002), all field aligned beams are excluded when one only select fast flows from a small region around the neutral sheet. The earthward and tailward currents are estimated from the combined magnetic field measurements from all spacecraft. We call such events current sheet coverages.

BBFs are often associated with a localized current wedge with an upward current at the duskward edge, and a downward current at the dawnward edge. Such currents have been predicted from theory (Pontius and Wolf, 1990), shown in simulations (e.g. Birn et al., 2004) and also observed (Sergeev et al., 1996; Nakamura et al., 2005; Snekvik et al., 2007). Even if such currents are present in the cases studied here, we argue later that they do not influence the statistical results found in the next sections.

The data presented in this paper are from the fluxgate magnetometer experiment (FGM - all spacecraft) (Balogh et al., 2001) and the Cluster Ion Spectrometry (CIS - three spacecraft) (Rème et al., 2001). CIS consists of two detectors, namely the Hot Ion Analyser (HIA), and the time-offlight ion Composition Distribution Function (CODIF). The plasma measurements used here are derived from proton data from CODIF at $\mathrm{C} 1$ and $\mathrm{C} 4$ and ion data from HIA at $\mathrm{C} 3$.

This paper is organised as follows. In Sect. 2 the method is described. Section 3 presents the results. The results are discussed in Sect. 4, and Sect. 5 concludes the paper.

\section{Method description}

We will now describe the method that is used to estimate the earthward current $j_{X}\left(Z_{n}\right)$, where $Z_{n}$ is the normalized distance in the current sheet. The relation between the current and the magnetic field is given by Ampére's law. Therefore, the expected value for $j_{X}\left(Z_{n}\right)$ can be written

$\mu_{0} \mu\left(j_{X}\left(Z_{n}\right)\right)=\mu\left(\frac{\partial B_{Z}}{\partial Y}\left(Z_{n}\right)\right)-\mu\left(\frac{\partial B_{Y}}{\partial Z}\left(Z_{n}\right)\right)$,

where $\mu$ denotes the expected value. If $\mu\left(\partial B_{Z} / \partial Y\left(Z_{n}\right)\right)=0$, the estimator of $\mu\left(j_{X}\left(Z_{n}\right)\right)$ will be

$\hat{\mu}\left(j_{X}\left(Z_{n}\right)\right)=-\frac{1}{\mu_{0}} \hat{\mu}\left(\frac{\partial B_{Y}}{\partial Z}\left(Z_{n}\right)\right)=-\frac{1}{\mu_{0}}\left\langle\frac{\partial B_{Y}}{\partial Z}\left(Z_{n}\right)\right\rangle$,

where $\hat{\mu}$ denotes the estimator of the expectation value, and \langle\rangle denotes the average of several independent events. The average is used as the estimator of the expectation value. The assumption $\mu\left(\partial B_{Z} / \partial Y\left(Z_{n}\right)\right)=0$, will be discussed in Sect. 4. The rest of this section is devoted to describe how we find $\hat{\mu}\left(\partial B_{Y} / \partial Z\left(Z_{n}\right)\right)$. 


\subsection{Plasma sheet time intervals}

The first step is to identify when Cluster is in the plasma sheet. These time intervals are defined from the magnitude of plasma $\beta$, the ratio between plasma to magnetic pressure. We refer to Baumjohann et al. $(1988,1989)$ for average values of plasma $\beta$ in the plasma sheet boundary layer (PSBL) and the central plasma sheet (CPS). Data from the three spacecraft with ion detectors are used to identify the intervals.

A plasma sheet time interval is defined in the following way:

a) Plasma $\beta>3$ in at least one sample during the interval. This corresponds to the inner CPS.

b) At least one of $\mathrm{C} 1, \mathrm{C} 3$ and $\mathrm{C} 4$ measures plasma $\beta>0.02$ at any time. This corresponds to the outer PSBL.

c) If there are no samples which fulfil b) within one minute of a given sample, the interval ends or starts at that sample.

d) A visual inspection is done for all time intervals. We restrict the area studied to $\left|Y_{\mathrm{GSM}}\right|< \pm 10 R_{E}$ and $X_{\mathrm{GSM}}$ between $-15 R_{E}$ and $-19 R_{E}$. In addition, time intervals with "unphysical" fluctuations in the ion data are excluded.

\subsubsection{Coordinate system}

For the event selection a coordinate frame based on the orientation of the current sheet is desired. At the distances studied here, the neutral sheet is oriented approximately parallel with the $X Y_{\mathrm{GSM}}$ plane on average (Kaymaz et al., 1994). Close to midnight the main component of the magnetic field is approximately along $X_{\mathrm{GSM}}$, but as the distance from midnight increases, it will get an increasing component along $Y_{\mathrm{GSM}}$ due to the flaring of the magnetotail (Kaymaz et al., 1994). To account for this, a variance analysis is done on the magnetic field in each orbit. The time interval used for the variance analysis lasts from the first entry until the last exit of the plasma sheet in each orbit. This can be done since Cluster has a polar orbit and thus stays at approximately the same local time in the plasma sheet in each orbit. The direction with maximum variance $\boldsymbol{l}$, is taken as the $\mathrm{X}$-direction. Khrabrov and Sonnerup (1998) showed that this is a good approximation for a current sheet where the current is unidirectional. The modified Y-direction is parallel with $\boldsymbol{Z}_{\mathrm{GSM}} \times \boldsymbol{l}$.

\subsection{Current sheet coverages}

In order to quantify the distance in the current sheet, it is approximated with a Harris sheet model where $Z_{n}$ is the normalized distance from the centre. On average, the main magnetic field component in the current sheet is well represented by a Harris current sheet (Kaymaz et al., 1994). The advantage with this model is that it is easy to implement for multiple spacecraft (see e.g. Nakamura et al., 2002).
In a Harris current sheet the normalized distance $Z_{n}$ can be found by a simple conversion of $B_{X}$ :

$$
\frac{B_{X}}{B_{L}}=\tanh \frac{\Delta Z}{D}=\tanh Z_{n} \Rightarrow Z_{n}=\tanh ^{-1} \frac{B_{X}}{B_{L}} .
$$

$\Delta Z$ is the distance from the centre of the current sheet, $D$ is the half-thickness of the current sheet and $B_{L}$ is the lobe magnetic field. Thus, a normalized distance can be calculated for each magnetic field sample. $B_{L}$ is found by assuming that the sum of the plasma and magnetic pressure in the plasma sheet equals the magnetic pressure in the lobe. According to Angelopoulos et al. (1994) the plasma pressure in the lobes usually is less than $0.01 \mathrm{nPa}$ and therefore negligible compared to the magnetic pressure.

Ideally, we would like "snapshots" of $B_{Y}$ perpendicular to the current sheet during earthward or tailward fast flows. On the other hand, it will take a finite time to get enough magnetic field samples. To solve this controversy between what is wanted and what is possible, we search for events where Cluster can obtain measurements for many different $Z_{n^{-}}$values in a short time interval. To be more precise, the current sheet is divided into 20 intervals between $Z_{n}=-0.4$ and $Z_{n}=1.6$ for the Northern Hemisphere (Fig. 2) or $Z_{n}=-1.6$ and $Z_{n}=0.4$ for the Southern Hemisphere. The bins are selected such that the current sheet is covered from the centre out to a distance where $B_{X}$ is about $91 \%$ of the lobe field. The reason that the first bin is in the opposite hemisphere at $Z_{n}= \pm 0.4$, is that several bins are used to estimate the current density as described in Sects. 2.3 and 2.4. All time intervals shorter than $5 \mathrm{~min}$ with at least one magnetic field sample in each bin can then be found. Magnetic field data sampled at $5 \mathrm{~Hz}$ from all satellites are used for this purpose. Such time intervals are called current sheet coverages in the following. Current sheet coverages are found from the time intervals where Cluster is in the plasma sheet as defined in Sect. 2.1. In order to study the relation between $B_{Y}$ and $Z_{n}$ statistically, all samples from current sheet coverages in the Southern Hemisphere are transformed as follows: $Z_{n} \rightarrow-Z_{n}$ and $B_{Y} \rightarrow-B_{Y}$.

$Z_{n}$ can only be used as a reliable measure of distance if the Harris sheet model is roughly correct or the thickness of the current sheet does not change too much. For each set of samples from the 4 spacecraft, the thickness of the current sheet is estimated. This is done based on Eq. (2) and the two spacecraft out of the four which are most separated along $Z_{n}$. Let $i$ and $o$ denote the innermost and the outermost spacecraft, respectively. The expression for the thickness can then be written

$D=\frac{Z_{\mathrm{o}}-Z_{\mathrm{i}}}{\tanh ^{-1} \frac{B_{\mathrm{X}_{\mathrm{o}}}}{B_{\mathrm{L}}}-\tanh ^{-1} \frac{B_{\mathrm{Xi}}}{B_{\mathrm{L}}}}$,

where $Z_{i}$ and $Z_{0}$ are the positions of the satelittes along the $Z$-axis. The mean and standard deviation of the thickness are then found for each coverage. We exclude events where 


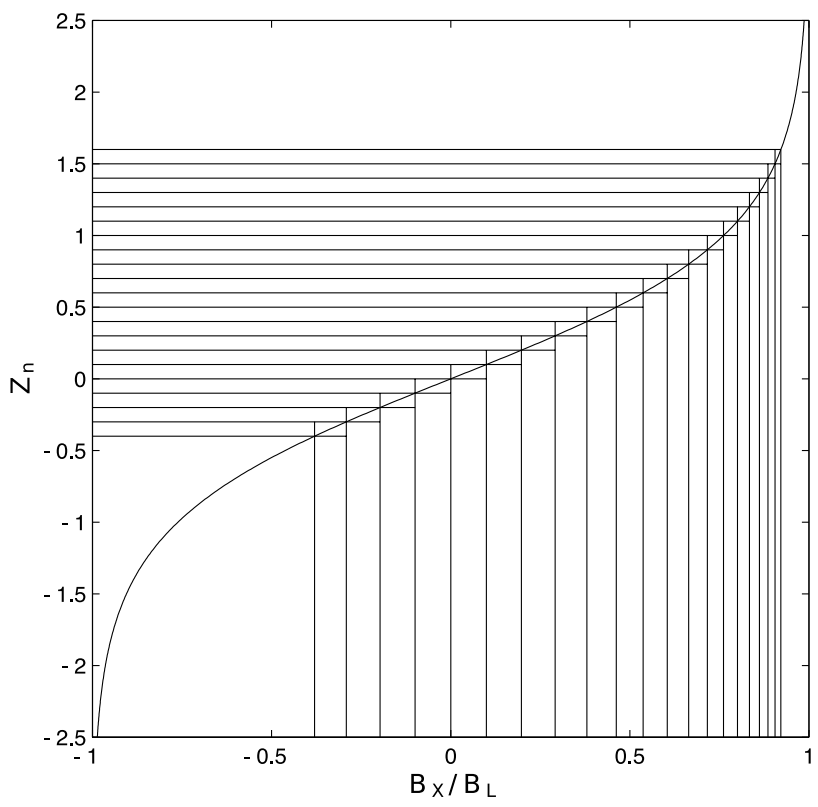

Fig. 2. A current sheet coverage is defined as a time interval where at least one magnetic field sample is obtained from each rectangle in the figure above in less than $5 \mathrm{~min}$. This figure is for current sheet coverages in the Northern Hemisphere.

the standard deviation is larger than the mean. This excludes events where the thickness changes significantly during the coverage. It may also exclude events where the current sheet deviates strongly from a Harris sheet, because the thickness estimated at different places in a non Harris current sheet would vary.

An example of a current sheet coverage is shown in Fig. 3. Measurements from $\mathrm{C} 1, \mathrm{C} 2, \mathrm{C} 3$ and $\mathrm{C} 4$ are shown with black, red, green and blue markers, respectively. This coverage is from 21 August 2002 between 08:16:57 UT and 08:18:09 UT. The half thickness of the current sheet is estimated to be $1800 \pm 400 \mathrm{~km}$. $B_{X}$ has the expected shape of a tangents hyperbolic, and it approaches about $30 \mathrm{nT}$ at large distances $\left(Z_{n}>2\right)$. This is interpreted as the value of $B_{X}$ in the lobe. $V_{X}$ reaches a magnitude of about $700 \mathrm{~km} / \mathrm{s}$ tailward in the centre of the current sheet. The functions $B_{Y}\left(Z_{n}\right)$ and $\partial B_{Y} / \partial Z\left(Z_{n}\right)$ are estimated and shown with gray bars in Fig. 3c and stars in Fig. 3d, respectively. These estimates will be discussed in the Sect. 2.3.

\subsection{Estimating $B_{Y}\left(Z_{n}\right)$ and $\partial B_{Y} / \partial Z\left(Z_{n}\right)$}

For each current sheet coverage the functions $B_{Y}\left(Z_{n}\right)$ and $\partial B_{Y} / \partial Z\left(Z_{n}\right)$ are estimated as shown in Fig. $3 c$ and d. They are estimated for a discrete set of $Z_{n}$ values. For a given $Z_{n}=z_{i}, B_{Y}\left(z_{i}\right)$ is calculated by taking the mean of all samples in the interval between $z_{i}-0.1$ and $z_{i}+0.1$, while $\partial B_{Y} / \partial Z\left(z_{i}\right)$ is calculated by a linear regression of the sam-

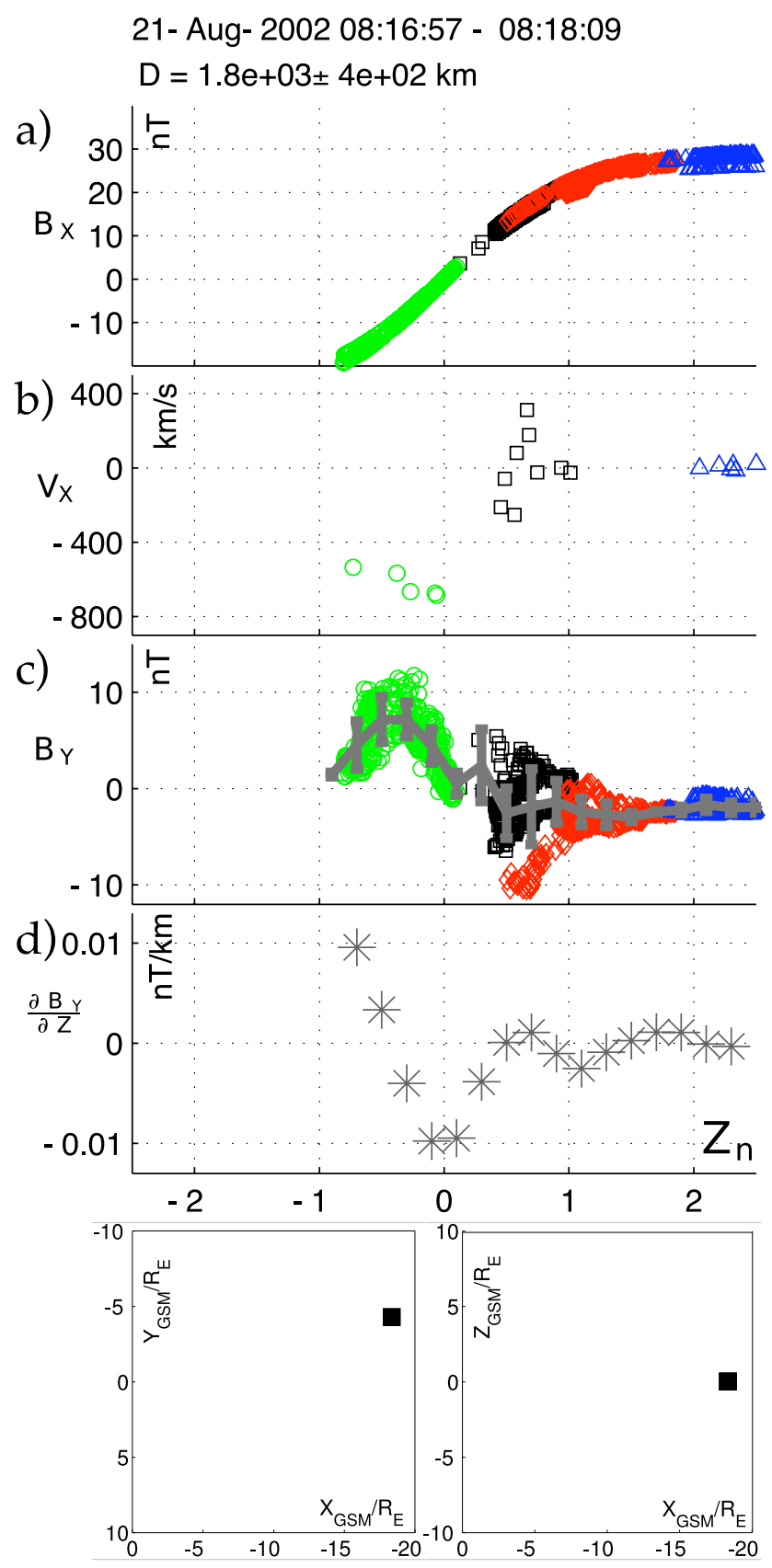

Fig. 3. An example of a current sheet coverage. The time interval and the estimated half thickness are shown at the top of the figure. All the scatter plots have the normalized distance, $Z_{n}$, on the horizontal axis. C1, C2, C3 and C4 are shown with black, red, green, and blue markers, respectively. (c) The estimated mean and sampling deviation for different $Z_{n}$-values are shown with gray bars. (d) The estimated slope of $B_{Y}\left(Z_{n}\right)$.

The bottom panel shows the position of Cluster in GSM.

ples in the interval between $z_{i}-0.3$ and $z_{i}+0.3$. The equation for the linear regression is $a_{1} Z_{n}+a_{2}$. By dividing $a_{1}$ with the estimated half thickness of the current sheet, $D$, one 
gets an estimate for $\partial B_{Y} / \partial Z\left(z_{i}\right)$. The reason why the estimator for the derivative is calculated from a wider interval than the mean, is to increase the confidence for the slope of the regression line.

\subsection{Estimating $j_{X}\left(Z_{n}\right)$}

Equation (1) suggests that the expected current density can be estimated by the average slope of $B_{Y}$ of all events for each $Z_{n}$ value. This technique resembles the superposed epoch analysis except that $Z_{n}$ replaces time. The advantage of taking the average is that it can reveal a common underlying pattern which in single events may be obfuscated by noise from other competing influences that operate at similar scales. This is in particular true for the plasma sheet, which is highly dynamic during fast flows, and it is often difficult to discriminate between temporal and spatial effects. The averages were calculated for earthward and tailward flows separately. The neutral sheet was defined to be where $\left|Z_{n}\right|<0.2$, and the magnitude of the flows had to exceed $200 \mathrm{~km} / \mathrm{s}$.

\section{Results}

3.1 Plasma sheet time intervals and current sheet coverages

102 current sheet coverages with a mean duration of $54 \mathrm{~s}$ were found in total. They were found from $237 \mathrm{~h}$ of Cluster data from the plasma sheet where the criteria in Sect. 2.1 were fulfilled. All current sheet coverages are from the area within $-15 R_{E}>X_{\mathrm{GSM}}>-19 R_{E}$ and $\left|Y_{\mathrm{GSM}}\right|<10 R_{E}$. The Cluster separation was about $4000 \mathrm{~km}$ at this time.

Baumjohann et al. (1990) found that ion bulk speed samples in excess of $400 \mathrm{~km} / \mathrm{s}$ amounts to $2.4 \%$ of all samples in the inner central plasma sheet. On the contrary, such samples are quite frequent during current sheet coverages. 93 and 74 out of 102 coverages have $|V|_{X \max }>200 \mathrm{~km} / \mathrm{s}$ and $|V|_{\mathrm{Xmax}}>400 \mathrm{~km} / \mathrm{s}$, respectively. In addition, 7 of the $9 \mathrm{cov}-$ erages with $|V|_{\mathrm{Xmax}}<200 \mathrm{~km} / \mathrm{s}$ are less than $4 \mathrm{~min}$ from another coverage with $|V|_{X \max }>200 \mathrm{~km} / \mathrm{s}$. Therefore, basically all current sheet coverages are associated with fast flows. We will come back to this in the Discussion. $\left|V_{X}\right|>200 \mathrm{~km} / \mathrm{s}$ in the neutral sheet $\left(\left|Z_{n}\right|<0.2\right)$ was satisfied for 63 of the current sheet coverages.

The current sheet coverages tend to occur in groups, and the median time between two consecutive coverages is only about $30 \mathrm{~s}$. Table 1 shows the time intervals when coverages were obtained.

\subsection{Average patterns}

43 and 20 current sheet coverages were found for earthward and tailward fast flows in the neutral sheet, respectively. They resulted in the average patterns shown in Fig. 4. The half-thickness of the current sheet $\left(Z_{n}=1\right)$ was $(2900 \pm 1200) \mathrm{km}$ for tailward flows and $(3100 \pm 1300) \mathrm{km}$ for
Table 1. Time intervals where current sheet coverages were obtained in 2002.

\begin{tabular}{cc}
\hline Time interval & Number of coverages \\
\hline 2 Aug 06:10-2 Aug 07:13 & 7 \\
6 Aug 18:28-6 Aug 18:30 & 1 \\
18 Aug 18:00-18 Aug 18:09 & 3 \\
21 Aug 07:59-21 Aug 08:31 & 38 \\
25 Aug 22:13-25 Aug 22:14 & 2 \\
28 Aug 10:07-28 Aug 10:20 & 8 \\
13 Sep 18:07-13 Sep 18:28 & 13 \\
13 Sep 22:33-13 Sep 22:35 & 1 \\
18 Sep 13:07-18 Sep 14:04 & 15 \\
20 Sep 21:14-20 Sep 21:16 & 2 \\
25 Sep 21:30-25 Sep 21:32 & 1 \\
2 Oct 17:20-2 Oct 17:21 & 1 \\
2 Oct 21:19-2 Oct 21:32 & 10 \\
\hline
\end{tabular}

earthward flows. The average current density is estimated from Eq. (1). Note that the current sheet coverages from the Southern Hemisphere have been transformed to positive $Z_{n}$ values before the average patterns were calculated.

For earthward flow there is a tailward current in the centre of the current sheet of about $2 \mathrm{nA} / \mathrm{m}^{2}$ and a weaker earthward current of about $1 \mathrm{nA} / \mathrm{m}^{2}$ closer to the lobe. The tailward current extend from the centre out to $Z_{n}=0.8$ where $B_{X}$ is $66 \%$ of the lobe field, and plasma $\beta_{X}$ is 1.3 where $\beta_{X}$ is only based on $B_{X}$. The earthward current is limited to $Z_{n}>1$ where the corresponding value of $B_{X}$ is $76 \%$ of the lobe field and the value of $\beta_{X}$ is 0.7 . For tailward flow the current is opposite and more than twice as strong, but otherwise the pattern is similar. The average $B_{Y}$-pattern is consistent with these currents.

\section{Discussion}

In this study the Cluster satellites have been used as fleet of single satellites. This enable them to cover a substantial part of the current sheet in a short time. This is in contrast to multi-spacecraft methods like the curlometer method (Robert et al., 1998) where only the value in the barycentre of the spacecraft is estimated. While this has the potential to give good quality estimates of the gradients when the spacecraft separation is small and they are in the same physical region, it comes at the expense of sampling only a fraction of the current sheet. This can for instance be seen from Fig. 3d. Our method enables us to estimate the derivative in a large part of the current sheet. The curlometer method could not be used in this case because of the large distance between the spacecraft, and it would in any case only give values in a limited region in the centre of the spacecraft. The tail season 2002 was chosen because the separation between the spacecraft 

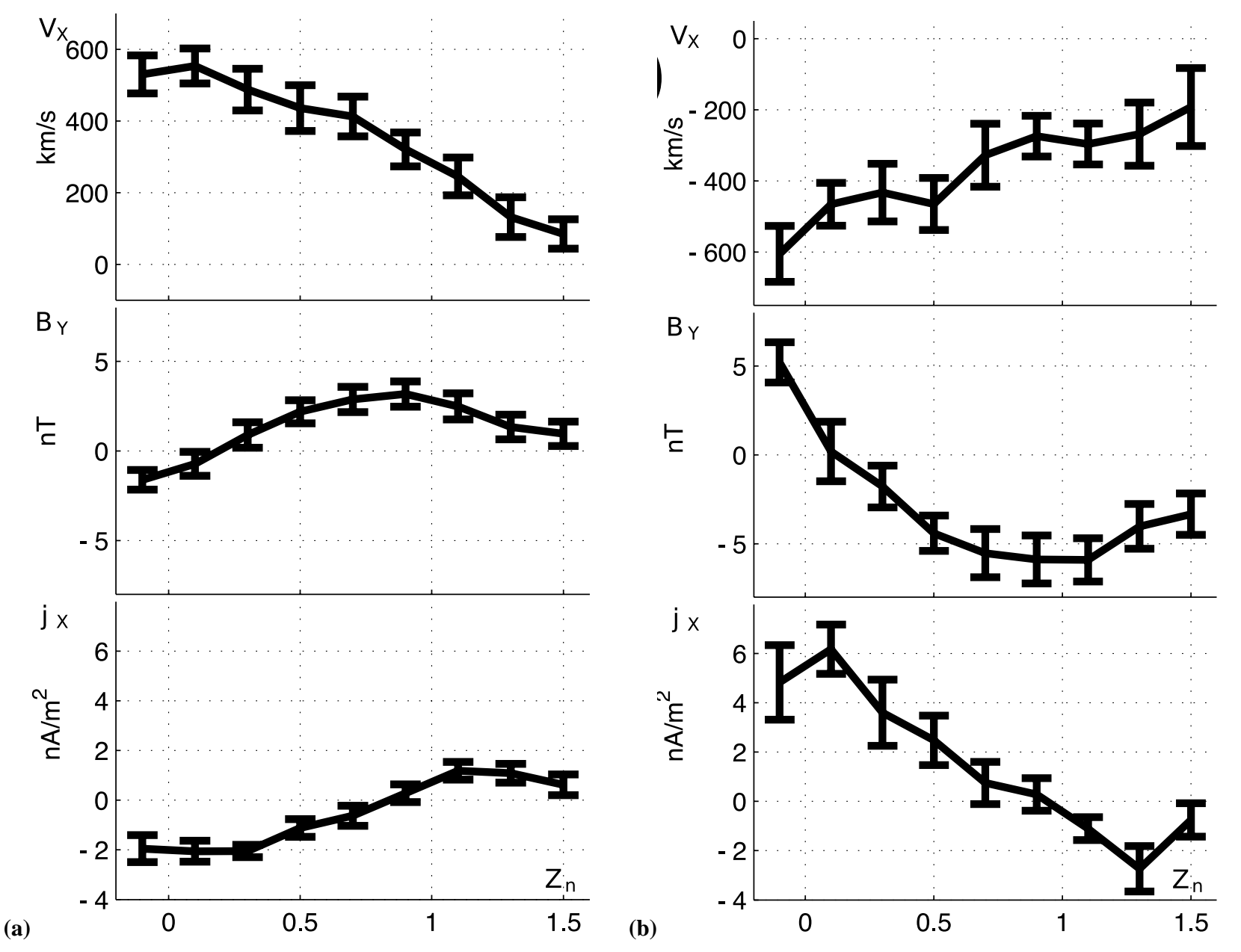

Fig. 4. The average patterns for earthward (a) and tailward (b) flows. $Z_{n}$ is the normalised distance from the centre of the current sheet. (a) and (b) are calculated from 43 and 20 current sheet coverages, respectively. One example of a current sheet coverage was shown in Fig. 3.

( $\sim 4000 \mathrm{~km})$ is ideal for sampling different parts of the current sheet simultaneously.

The total time of the current sheet coverages was $1.53 \mathrm{~h}$. This amounts to only $0.65 \%$ of the $237 \mathrm{~h}$ Cluster spent in the plasma sheet between 2 August and 2 October 2002. The main reason for this is that the satellites must be able to obtain data from 20 different positions in the current sheet as shown in Fig. 2 in less than five minutes. On this time scale Cluster can be considered to be at rest, while the current sheet may move relative to the spacecraft. The current sheet motion could either be caused by external or internal forces. The fact that almost all coverages are associated with fast flows, strongly suggest this to have internal origin.

As mentioned in the beginning of Sect. 2, it must be assumed that the expectation value $\mu$, of $\partial B_{Z} / \partial Y\left(Z_{n}\right)$ is zero for the preceding results to be valid. This does not mean that $\partial B_{Z} / \partial Y\left(Z_{n}\right)$ itself is negligible. For instance, earthward bulk flows are often associated with enhanced $B_{Z}$ (e.g. Raj et al., 2002) in a narrow flow channel (Nakamura et al., 2004a) with $\partial B_{Z} / \partial Y>0$ and $\partial B_{Z} / \partial Y<0$ at its dawn and dusk side, respectively. This imply tailward and earthward field aligned currents. However, $\mu\left(\partial B_{Z} / \partial Y\left(Z_{n}\right)\right)=0$ means that it is equally probable that the spacecraft is in a position where $\partial B_{Z} / \partial Y$ is positive as well as negative. Or for the case of flow channels, that the spacecraft is at the dawn as well as at the dusk side. This also means that the current at the flanks of a bulk flow will not show up in the average patterns in Fig. 4, but rather contribute to the error bars. As a check we have also made average patterns for $Y_{\mathrm{GSM}}>0$ and $Y_{\mathrm{GSM}}<0$ (not shown). This gave no statistically significant differences.

The currents are most easily interpreted if one assumes that the source of the fast flows is an X-line. The fact that 43 and 20 of the current sheet coverages had earthward and tailward flows, respectively, indicates that the X-line is tailward of the satellites on average. This is in accordance with Geotail data which indicate that the $\mathrm{X}$-line is located between $X_{\mathrm{GSM}}=-30 R_{E}$ and $X_{\mathrm{GSM}}=-20 R_{E}$ (Nagai and Machida, 
1998; Nagai et al., 1998). In that case, the currents may be explained as Hall currents or field aligned currents which close with the Hall currents. In this picture the current in the centre is downstream of the $\mathrm{X}$-line, and the current closer to the lobe is upstream. The upstream current will not be detected when the X-line reconnects open field lines because this would be outside the region studied here. This may explain why the current in the centre is so much stronger.

The $B_{Y}$ patterns found here closely resemble those found by Ueno et al. (2003) around the magnetic neutral line. They identified 4022 simultaneous flow reversals and change in polarity of $B_{Z}$ with Geotail. They grouped the events according to the sign of $B_{Z}$ instead of the direction of flow. It is interesting that we get a similar result when we only use fast flow in the neutral sheet as the selection criterion. This indicates that the quadrupolar pattern often associated with reconnection is caused by current loops which extends far away from the reconnection site. Our result agree with earlier observations by Fujimoto et al. (2001), Nakamura et al. (2004a) and Runov et al. (2008). However, we can not determine the distance to the $\mathrm{X}$-line with our technique.

In Fig. 4 there is a strong asymmetry of the magnitudes of $B_{Y}$ and $j_{X}$ for earthward and tailward flows. This should in some way reflect different boundary conditions in the two cases. In fact, the average values of the lobe magnetic field are $24 \mathrm{nT}$ and $30 \mathrm{nT}$ for earthward and tailward flows, respectively. This corresponds to an energy density in the lobes which is $56 \%$ higher for tailward flows compared to earthward flows. Another factor is that the X-line must be further earthward when Cluster measures tailward flows than when they measure earthward flows. It is not possible to conclude from our data set whether the difference is due to the position of the X-line, the lobe magnetic field or if it really is an asymmetry of the two outflow regions. However, the last alternative is unlikely since Ueno et al. (2003) did not see any strong asymmetry around the neutral line with Geotail data.

The width of the currents $\left(j_{X}\right)$ in Fig. 4 is probably exaggerated. This may happen if the position of the currents are a bit different in the different current sheet coverages used to calculate the average patterns. Another uncertainty is the choice of current sheet model. The current sheet is often bifurcated during fast flows (Nakamura et al., 2002; Sitnov et al., 2007). However, this should not alter our result in any significant way. In the worst case, if this is a systematic error, it would only deform the patterns in Fig. 4, but it can not change the sign of the current densities.

It is interesting that the current reversal on average happens so deep inside the plasma sheet. Both for earthward and tailward flows the change in polarity takes place for $B_{X} \approx 0.7 B_{\text {lobe }}$ and plasma $\beta_{X} \approx 0.9$. The statistical study by Nagai et al. (2001) indicates that the outward current is related to electrons streaming towards the X-line in the inflow region. If this is the case, it means that the inflow region is on closed field lines inside the plasma sheet in our data set.

\section{Conclusions}

In this paper we have studied the average spatial distribution of $j_{X}$ in the current sheet during fast flows $\left(\left|V_{X}\right|>200 \mathrm{~km} / \mathrm{s}\right)$ in the neutral sheet. The patterns are as one would expect earthward and tailward of the X-line due to the Hall currents produced there. There is a tailward current in the inner central plasma sheet of about $2 \mathrm{nA} / \mathrm{m}^{2}$ and a weaker earthward current of about $1 \mathrm{nA} / \mathrm{m}^{2}$ in the outer central plasma sheet for earthward fast flows. For tailward fast flows the pattern is opposite with earthward current in the inner central plasma sheet and tailward current in the outer central plasma sheet. The magnitude of the currents is about twice as large for tailward fast flows. Furthermore, the average energy density in the lobes are 56\% higher during tailward flows. We can not say for sure if this is the reasons for the higher currents at the tailward side.

Acknowledgements. We thank K. M. Laundal for helpful discussions and comments and H.-U. Eichelberger for making Cluster FGM data available. We acknowledge the Cluster CIS PI Iannis Dandouras and the Cluster FGM PI Elizabeth Lucek.

Editor-in-Chief W. Kofman thanks one anonymous referee for her/his help in evaluating this paper.

\section{References}

Angelopoulos, V., Baumjohann, W., Kennel, C. F., Coroniti, F. V., Kivelson, M. G., Pellat, R., Walker, R. J., Lühr, H., and Paschmann, G.: Bursty bulk flows in the inner central plasma sheet, J. Geophys. Res., 97, 4027-4039, 1992.

Angelopoulos, V., Kennel, C. F., Coroniti, F. V., Pellat, R., Kivelson, M. G., Walker, R. J., Russell, C. T., Baumjohann, W., Feldman, W. C., and Gosling, J. T.: Statistical characteristics of bursty bulk flow events, J. Geophys. Res., 99, 21 257-21 280, 1994.

Asano, Y., Nakamura, R., Baumjohann, W., Runov, A., Vörös, Z., Volwerk, M., Zhang, T. L., Balogh, A., Klecker, B., and Rème, H.: How typical are atypical current sheets?, Geophys. Res. Lett., 32, L03108, doi:10.1029/2004GL021834, 2005.

Balogh, A., Carr, C. M., Acũna, M. H., Dunlop, M. W., Beek, T. J., Brown, P., Fornacon, K.-H., Georgescu, E., Glassmeier, K.-H., Harris, J., Musmann, G., Oddy, T., and Schwingenschuh, K.: The Cluster Magnetic Field Investigation: Overview of in-flight performance and initial results, Ann. Geophys., 19, 1207-1217, 2001, http://www.ann-geophys.net/19/1207/2001/.

Baumjohann, W., Paschmann, G., Sckopke, N., Cattell, C. A., and Carlson, C. W.: Average Ion Moments in the Plasma Sheet Boundary Layer, J. Geophys. Res., 93, 11 507-11 520, 1988.

Baumjohann, W., Paschmann, G., and Cattell, C. A.: Average Plasma Properties in the Central Plasma Sheet, J. Geophys. Res., 94, 6597-6606, 1989.

Baumjohann, W., Paschmann, G., and Lühr, H.: Characteristics of high speed ion flows in the plasma sheet, J. Geophys. Res., 95, 3801-3809, 1990.

Birn, J., Raeder, J., Wang, Y. L., Wolf, R. A., and Hesse, M.: On the propagation of bubbles in the geomagnetic tail, Ann. Geophys., 
22, 1773-1786, 2004,

http://www.ann-geophys.net/22/1773/2004/.

Cao, J. B., Ma, Y. D., Parks, G., Rème, H., Dandouras, I., Nakamura, R., Zhang, T. L., Zong, Q., Lucek, E., Carr, C. M., Liu, Z. X., and Zhou, G. C.: Joint observations by Cluster satellites of bursty bulk flows in the magnetotail, J. Geophys. Res., 111, A04206, doi:10.1029/2005JA011322, 2006.

Dungey, J. W.: Interplanetary magnetic field and the auroral zones, Phys. Rev. Lett., 6, 47-48, 1961.

Fujimoto, M., Nagai, T., Yokokawa, N., Yamade, Y., Mukai, T., Saito, Y., and Kokubun, S.: Tailward electrons at the lobe-plasma sheet interface detected upon dipolarizations, J. Geophys. Res., 106, 21 255-21 262, 2001.

Kaymaz, Z., Siscoe, G. L., Tsyganenko, N. A., and Lepping, R. P.: Magnetotail views at $33 R_{E}$ : IMP 8 magnetometer observations, J. Geophys. Res., 99, 8705-8730, 1994.

Keiling, A., Wygant, J. R., Cattell, C., Johnson, M., Temerin, M., Mozer, F. S., Kletzing, C. A., Scudder, J., and Russel, C. T.: Properties of large electric fields in the plasma sheet at 4-7 $R_{E}$ measured with Polar, J. Geophys. Res., 106, 5779-5798, 2001.

Khrabrov, A. V. and Sonnerup, B. U. Ö.: Error estimates for minimum variance analysis, J. Geophys. Res., 103, 6641-6651, 1998.

Nagai, T., Fujimoto, M., Saito, Y., Machida, S., Terasawa, T., Nakamura, R., Yamamoto, T., Mukai, T., Nishida, A., and Kokubun, S.: Structure and dynamics of magnetic reconnection for substorm onsets with Geotail observations, J. Geophys. Res., 103, 4419-4440, 1998.

Nagai, T., Shinohara, I., Fujimoto, M., Hoshino, M., Saito, Y., Machida, S., and Mukai, T.: Geotail observations of the Hall current system: Evidence of magnetic reconnection in the magnetotail, J. Geophys. Res., 106, 25 929-25 949, 2001.

Nagai, T. and Machida, S.: Magnetic Reconnection in the NearEarth Magnetotail, in: New Perspectives on the Earth's Magnetotail, vol. 105 of Geophysical Monograph, pp. 211-224, American Geophysical Union, 1998.

Nakamura, R., Baumjohann, W., Runov, A., Volwerk, M., Zhang, T. L., Klecker, B., Bogdanova, Y., Roux, A., Balogh, A., Rème, H., Sauvaud, J. A., and Frey, H. U.: Fast flow during current sheet thinning, Geophys. Res. Lett., 29, 2140, doi:10.1029/2002GL016200, 2002.

Nakamura, R., Baumjohann, W., Mouikis, C., Kistler, L. M., Runov, A., Volwerk, M., Asano, Y., Vörös, Z., Zhang, T. L., Klecker, B., Rème, H., and Balogh, A.: Spatial scale of high-speed flows in the plasma sheet observed by Cluster, Geophys. Res. Lett., 31, L09804, doi:10.1029/2004GL019558, 2004a.

Nakamura, R., Baumjohann, W., Nagai, T., Fujimoto, M., Mukai, T., Klecker, B., Treumann, R., Balogh, A., Rème, H., Sauvaud, J. A., Kistler, L., Mouikis, C., Owen, C. J., Fazakerley, A. N., Dewhurst, J. P., and Bogdanova, Y.: Flow shear near the boundary of the plasma sheet observed by Cluster and Geotail, J. Geophys. Res., 109, A05204, doi:10.1029/2003JA010174, 2004b.

Nakamura, R., Amm, O., Laakso, H., Draper, N. C., Lester, M., Grocott, A., Klecker, B., McCrea, I. W., Balogh, A., Rème, H., and André, M.: Localized fast flow disturbance observed in the plasma sheet and in the ionosphere, Ann. Geophys., 23, 553566, 2005, http://www.ann-geophys.net/23/553/2005/.

Pontius, D. H. and Wolf, R. A.: Transient flux tubes in the terrestrial magnetosphere, Geophys. Res. Lett., 17, 49-51, 1990.
Raj, A., Phan, T., Lin, R. P., and Angelopoulos, V.: Wind survey of high-speed bulk flows and field-aligned beams in the near-Earth plasma sheet, J. Geophys. Res., 107, 1419, doi:10.1029/2001JA007547, 2002.

Rème, H., Aoustin, C., Bosqued, J. M., Dandouras, I., Lavraud, B., Sauvaud, J. A., Barthe, A., Bouyssou, J., Camus, T., CoeurJoly, O., Cros, A., Cuvilo, J., Ducay, F., Garbarowitz, Y., Medale, J. L., Penou, E., Perrier, H., Romefort, D., Rouzaud, J., Vallat, C., Alcaydé, D., Jacquey, C., Mazelle, C., Uston, C. D., Mobius, E., Kistler, L. M., Crocker, K., Granoff, M., Mouikis, C., Popecki, M., Vosbury, M., Klecker, B., Hovestadt, D., Kucharek, H., Kuenneth, E., Paschmann, G., Scholer, M., Sckopke, N., Seidenschwang, E., Carlson, C. W., Curtis, D. W., Ingraham, C., Lin, R. P., McFadden, J. P., Parks, G. K., Phan, T., Formisano, V., Amata, E., Bavassano-Cattaneo, M. B., Baldetti, P., Bruno, R., Chionchio, G., Lellis, A. D., Marcucci, M. F., Pallocchia, G., Korth, A., Daly, P. W., Graeve, B., Rosenbauer, H., Vasyliunas, V., McCarthy, M., Wilber, M., Eliasson, L., Lundin, R., Olsen, S., Shelley, E. G., Fuselier, S., Ghielmetti, A. G., Lennartsson, W., Escoubet, C. P., Balsiger, H., Friedel, R., Cao, J.-B., Kovrazhkin, R. A., Papamastorakis, I., Pellat, R., Scudder, J., and Sonnerup, B.: First multispacecraft ion measurements in and near the Earth's magnetosphere with the identical Cluster ion spectrometry (CIS) experiment, Ann. Geophys., 19, 1303-1354, 2001,

http://www.ann-geophys.net/19/1303/2001/.

Robert, P., Dunlop, M. W., Roux, A., and Chanteur, G.: Accuracy of Current Density Determination, in: Analysis Methods for MultiSpacecraft Data, edited by: Paschmann, G. and Daly, P. W., pp. 395-418, International Space Science Institute, Hallerstrasse 6, 3012 Bern, Switzerland, 1998.

Runov, A., Nakamura, R., Baumjohann, W., Treumann, R. A., Zhang, T. L., Volwerk, M., Vörös, Z., Glaßmeier, K.-H., Klecker, B., Rème, H., and Kistler, L.: Current sheet structure near magnetic X-line observed by Cluster, Geophys. Res. Lett., 30, 1579, doi:10.1029/2002GL016730, 2003.

Runov, A., Voronkov, I., Asano, Y., Baumjohann, W., Fujimoto, M., Nakamura, R., Takada, T., Volwerk, M., Vörös, Z., Meurant, M., Fazakerely, A., Rème, H., and Balogh, A.: Structure of the near-Earth plasma sheet during tailward flows, Ann. Geophys., 26, 709-724, 2008, http://www.ann-geophys.net/26/709/2008/.

Schödel, R., Baumjohann, W., Nakamura, R., and Mukai, V. A. S. T.: Rapid flux transport in the magnetotail, J. Geophys. Res., 106, 301-313, 2001.

Sergeev, V. A., Angelopoulos, V., Gosling, J. T., Cattell, C. A., and Russel, C. T.: Detection of localized, plasma-depleted flux tubes or bubbles in the midtail plasma sheet, J. Geophys. Res., 101, 10 817-10 826, 1996.

Sitnov, M. I., Guzdar, P. N., and Swisdak, M.: Atypical current sheets and plasma bubbles: A self-consistent kinetic model, Geophys. Res. Lett., 34, L15101, doi:10.1029/2007GL029693, 2007.

Snekvik, K., Haaland, S., Østgaard, N., Hasegawa, H., Nakamura, R., Takada, T., Juusola, L., Amm, O., Pitout, F., Klecker, B., and Lucek, E. A.: Cluster observations of a field aligned current at the dawn flank of a bursty bulk flow, Ann. Geophys., 25, 14051415, 2007, http://www.ann-geophys.net/25/1405/2007/.

Sonnerup, B. U. Ö.: Magnetic field reconnection, Solar System 
Plasma Physics, III, 45-108, 1979.

Treumann, R. A., Jaroschek, C. H., Nakamura, R., Runov, A., and Scholera, M.: The role of the Hall effect in collisionless magnetic reconnection, Adv. Space Res., 38, 101-111, 2006.

Ueno, G., Ohtani, S., Mukai, T., Saito, Y., and Hayakawa, H.: Hall current system around the magnetic neutral line in the magnetotail: Statistical study, J. Geophys. Res., 108, 1347, doi: 10.1029/2002JA009733, 2003.
Wygant, J. R., Keiling, A., Cattell, C. A., Johnson, M., Lysak, R. L., Temerin, M., Mozer, F. S., Kletzing, C. A., Scudder, J. D., Peterson, W., Russel, C. T., Parks, G., Brittnacher, M., Germany, G., and Spann, J.: Polar spacecraft based comparisons of intense electric fields and Poynting flux near and within the plasma sheet-tail lobe boundary to UVI images: An energy source for the aurora, J. Geophys. Res., 105, 18 675-18 692, 2000.

Yamade, Y., Fujimoto, M., Yokokawa, N., and Nakamura, M. S.: Field-aligned currents generated in magnetotail reconnection: 3D Hall-MHD simulations, Geophys. Res. Lett., 27, 1091-1094, 2000. 